\title{
Prospective Evaluation of Zirconia Posterior Fixed Partial Dentures: Four-Year Clinical Results
}

\author{
Matthias Roediger, Dr Med Dent ${ }^{\mathrm{a}} /$ Nikolaus Gersdorff, Dr Med Dent ${ }^{\mathrm{a}} /$ \\ Alfons Huels, Prof Dr Med, Dr Med Dent ${ }^{\mathrm{b}} /$ Sven Rinke, Dr Med Dent, $\mathrm{MSc}^{\mathrm{c}}$
}

\begin{abstract}
Purpose: In this prospective clinical study, the performance of three- and four-unit fixed partial dentures (FPDs) with frameworks fabricated of yttria partially stabilized zirconia was determined after a mean observation period of 50 months. The study focused on the survival of the restoration (in situ criterion) and the success of the ceramic veneers (no defect). Materials and Methods: Seventy-five patients with a maximum of two missing teeth and an antagonistic dentition were treated at the Department of Prosthodontics, University of Goettigen, with 99 posterior FPDs. Fiftyone specimens (experimental group) were veneered with an experimental ceramic suitable for titanium and zirconia frameworks (thermal expansion coefficient [TEC]: 8.5 $\left.\mu \mathrm{m} / \mathrm{m}^{*} \mathrm{~K}\right) ; 48$ restorations (Ceram-S group) were veneered with a commercially available low-fusing ceramic optimized for zirconia frameworks (TEC: $9.5 \mu \mathrm{m} / \mathrm{m}^{*} \mathrm{~K}$ ). All restorations were luted with zinc-phosphate cement. Statistical analysis was performed according to the Kaplan-Meier method; time-dependent success rates of the different types of ceramic veneers were analyzed using the log-rank test. Results: Seven restorations were lost: 4 due to technical complications and 3 due to biologic complications. The overall survival rate after 48 months was 94\% (Kaplan-Meier analysis). Twenty-three events required clinical intervention for restoration maintenance: 13 ceramic veneer chippings (polishing), 6 losses of retention (recementation), 3 caries lesions (filling therapy), and 1 loss of vitality (endodontic treatment). Between the two groups of veneering materials, no significant difference in the probability for success was determined (log-rank test, $P=.81$ ). Conclusions: Within a mean observation period of 4 years, sufficient survival rates for zirconia-based posterior FPDs could be verified. The main complications included fracture of the ceramic veneering material and decementation, which occurred mainly in the mandible. Int J Prosthodont 2010;23:141-148.
\end{abstract}

\footnotetext{
${ }^{a}$ Researcher, Department of Prosthodontics, Georg-AugustUniversity, Goettingen, Germany.

bProfessor, Department of Prosthdontics, Georg-August-University, Goettingen, Germany.

cPrivate Practice, Hanau, Germany.
}

Correspondence to: Dr Matthias Roediger, Department of Prosthodontics, Georg-August-University, Goettingen, RobertKoch-Str. 40, 37075 Goettingen, Germany. Fax: +495513922897. Email:mroedig@gwdg.de success for fixed partial dentures (FPDs). ${ }^{1}$ The fracture resistance of the frameworks and veneering materials, as well as the resulting survival rates, were significantly lower for all-ceramic FPDs than for metal-ceramic restorations. ${ }^{2}$ The first all-ceramic system recommended for use in anterior FPDs was a glass-infiltrated aluminum oxide ceramic material (In-Ceram, Vita Zahnfabrik). However, clinical studies on In-Ceram alumina FPDs reported high rates of framework fracture in the posterior region. ${ }^{3,4}$ Clinical observations for lithium-disilicate ceramics also revealed a high complication and failure rate for all-ceramic FPDs in the posterior region. ${ }^{5}$ Compared to these findings, the reported failure rate for metalceramic FPDs was significantly lower. ${ }^{6-8}$ Poly crystalline zirconia ceramics show the highest bending strength and fracture resistance of all 
currently applied dental ceramic materials. A recently developed computer-aided design/computerassisted manufacturing (CAD/CAM) technology allows for the processing of this material. Results from in vitro ${ }^{9}$ and the first midterm clinical studies ${ }^{10-12}$ already suggest a promising applicability of this material for FPD frameworks in the posterior region. Therefore, all-ceramic restorations are no longer limited to the esthetically challenging anterior region. They can now be used in the replacement of both premolars and molars.

Apart from the well-documented stability of the zirconia framework, defects and chippings of the ceramic veneers were reported as clinical complications for this type of restoration. ${ }^{10-13}$ Clinical consequences of a defect of the veneering material can range from a simple polishing to the replacement of the restoration if the defect impairs either function or esthetics. Therefore, the durability of the veneering material is an important factor in the long-term performance of a restoration. Various assumptions on the source of error for the observed defects have been made, especially in the molar region. One assumption, based on the observations of metalceramic restorations, is that a possible source of error for these complications might be an incorrect match between the thermal expansion coefficient (TEC) of the framework and that of the veneering material. ${ }^{10}$

The aim of this study was to evaluate the longterm survival of conventionally cemented zirconiabased posterior three- and four-unit FPDs veneered with two types of veneering ceramics with different TECs: $8.5 \mu \mathrm{m} / \mathrm{m}^{*} \mathrm{~K}$ and $9.5 \mu \mathrm{m} / \mathrm{m}^{*} \mathrm{~K}$. The null hypothesis was that there would be no difference in the durability or complication rate between the two veneering materials.

\section{Materials and Methods}

\section{Patient Selection}

Seventy-five patients (36 women, 39 men) participated in this study. They were not members of the preor postdoctoral education programs of the Department of Prosthodontics at the University of Goettingen, where the study took place. The age of the subjects ranged from 26 to 76 years (mean: 49.4 \pm 12.4 years). Inclusion criteria were antagonistic teeth in the area of the restoration, vital abutments or abutments with sufficient endodontic treatment, and a maximum of two missing teeth. Patients with one or more of the following diagnoses were excluded from participation: bruxism, severe periodontal disease, pulpitis, and a horizontal abutment tooth mobility of $\geq 1 \mathrm{~mm}$. Patients were informed of the purpose of the investigation, the clinical procedures, and the advantages and risks of the applied material. The study was approved by the local ethics committee.

\section{Clinical Approach}

Clinical treatment was performed by experienced clinicians for all but 2 FPDs, which were treated by students under the supervision of a dental clinician. All patients received oral hygiene instructions and a professional tooth cleaning prior to prosthetic treatment. Patients received up to 4 FPDs. A total of 99 restorations ( 81 three-unit, 18 four-unit) were inserted (39 in the maxilla, 60 in the mandible). The allocation of pontics is shown in Figs 1a and 1b. For the majority of abutment teeth, a composite resin was used for the core buildup. Abutment teeth were prepared using a $0.8-$ to $1.0-\mathrm{mm}$ heavy chamfer and a minimum axial taper of 6 degrees (according to the Cercon Clinical Guide). The occlusal reduction was approximately $1.5 \mathrm{~mm}$. Impressions were taken with a polyether material (Impregum, 3M ESPE). Finally, the restorations were luted with a zinc-phosphate cement (Harvard, Richter and Hoffmann). The preferred occlusal concepts were a canine-protected articulation or a group function on the canines and premolars.

\section{Laboratory Techniques}

All frameworks were produced by a CAD/CAM system (Cercon smart ceramics, DeguDent), which was introduced to the German market in 2001. During the production process, a wax pattern of the framework is laser-scanned to acquire the necessary data for a three-dimensional virtual model. With this information, the zirconia restoration is milled from a soft presintered zirconia blank, which is then sintered to its final density.

Ninety-seven restorations were fabricated from noncolored blanks. The remaining 2 restorations were milled from a dentin-colored presintered material (Cercon base colored, DeguDent). The minimum framework thickness was $0.4 \mathrm{~mm}$ and the cross sections of the connector adhering at the abutment were at least $9 \mathrm{~mm}^{2}$. The frameworks manufactured in 2001 (experimental group, 51 units) were veneered with an experimental layering ceramic. This material was designed for the veneering of titanium and zirconia frameworks and therefore had an intermediate TEC of $8.5 \mu \mathrm{m} / \mathrm{m}^{*} \mathrm{~K}$. Since 2002, a ready-tomarket veneering material (Cercon Ceram-S, DeguDent) with a TEC optimized for the veneering of zirconia frameworks $\left(9.5 \mu \mathrm{m} / \mathrm{m}^{*} \mathrm{~K}\right)$ was used for 48 specimens (Ceram-S group). 

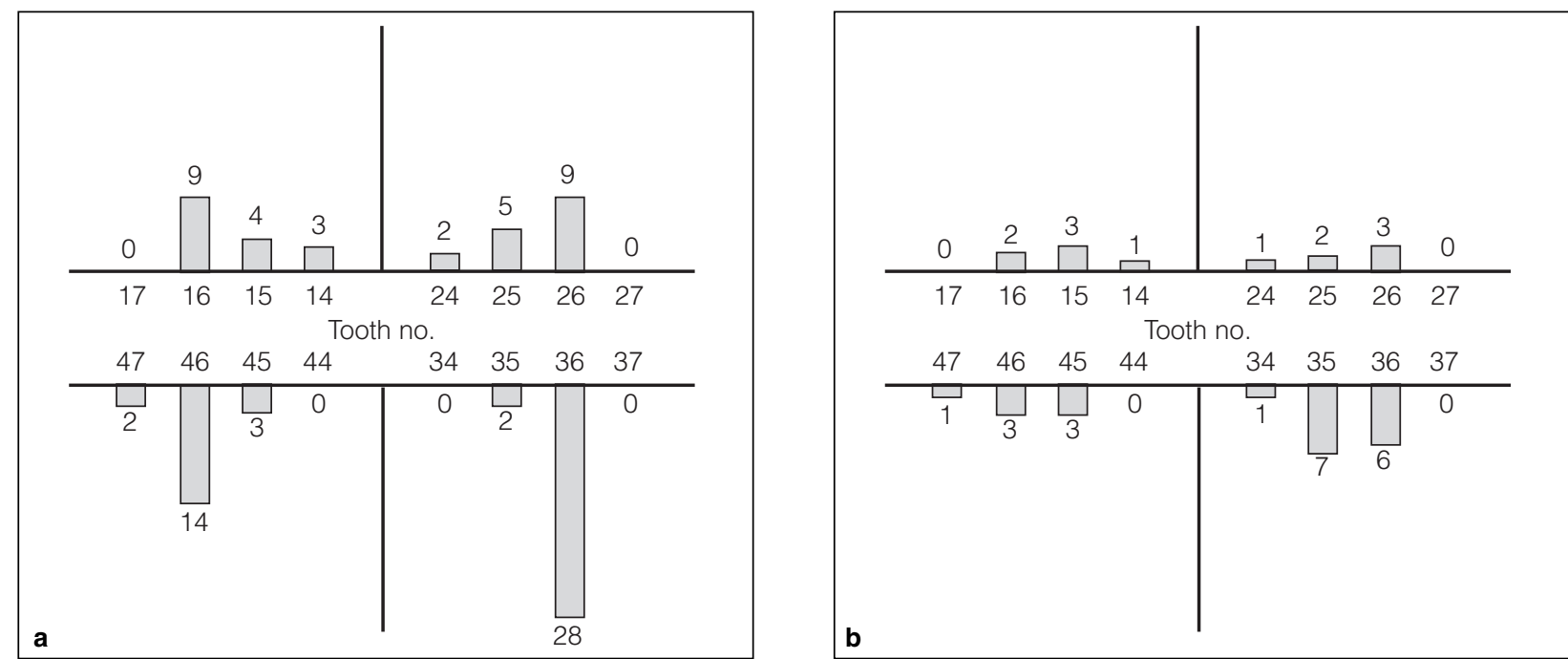

Figs 1a and 1b Allocation of pontics (replaced teeth) shown in a modified FDI two-digit notation for (a) three-unit FPDs and (b) fourunit FPDs. Note: three restorations were based on three abutment teeth for four-unit FPDs.

\section{Evaluation Procedures}

The examinations started at the point of final cementation (baseline). To determine the points of potential complications as precisely as possible, restorations were reevaluated continuously in 6-month intervals. The following parameters were assessed: decementation (mobility), loss of vitality of the abutment teeth (cold spray test), need for endodontic treatment, marginal integrity, secondary caries, fracture of the framework, and chipping of the ceramic veneer. Additionally, patients were asked about an increased abutment tooth sensitivity and chewing problems. Survival was defined according to the in situ criterion. All restorations that remained in function during the observation period were included. Veneers were defined as being successful if they remained event free without any clinical intervention (eg, chipping) during the evaluation period. In case of retention loss, the respective cast was investigated regarding the height of the preparation and the cone angle. This evaluation allowed for the analysis of a possible relation between the loss of retention and noticeably short or cone-shaped preparations.

\section{Statistical Analysis}

All complications leading to a replacement of the current FPD (technical and biologic complications) were defined as total failures. The survival time of the restoration was defined as the period between the day of final cementation and the last follow-up appointment or, in case of a failure, the appointment scheduled to address the failure. The success of the ceramic veneers was defined as event-free survival without any chipping of the material. The survival rates of the restorations (in situ criterion) and the success rates of the ceramic veneers (no defects) were calculated according to the Kaplan-Meier method. Data were excluded if patients were lost to follow-up or declined further participation in the study. To compare the success probabilities (time to event) of the two types of ceramic veneers, the logrank test was applied.

\section{Results}

During the observation period, 7 of the 99 inserted FPDs failed and had to be replaced; all of these specimens were three-unit FPDs (Table 1). Eight patients were lost to follow-up or declined further participation in the study (8 patients with 1 restoration each; 5 in the experimental group, 3 in the Ceram-S group; 7 three-unit FPDs, 1 four-unit FPD). Their data were excluded from further statistical evaluation. The overall survival rate (in situ criterion) according to the Kaplan-Meier method was 94\% after 48 months. Four restorations failed for technical reasons: 1 core fracture (marginal chipping) occurred and led to replacement of the restoration (Fig 2). The overall framework survival rate was $98.9 \%$. Three additional failures (experimental group), a result of loss of retention, could not be recemented because of progressed secondary caries. Another 3 failures were caused by biologic complications: 1 longitudinal root fracture of an endodontically treated premolar, 1 abutment loss due to a severe periodontal lesion, and 1 due to a progressed marginal caries lesion. 
Table 1 Reasons for Failures of the FPDs

\begin{tabular}{lccc}
\hline Reason for failure & Total $(\mathrm{n}=99)$ & $\begin{array}{c}\text { Experimental } \\
\text { group }(\mathrm{n}=51)\end{array}$ & $\begin{array}{c}\text { Ceram-S } \\
\text { group (n = 48) }\end{array}$ \\
\hline $\begin{array}{l}\text { Technical complications } \\
\text { Core fracture }\end{array}$ & 1 & 1 & 0 \\
Retention loss/resultant caries & 3 & 2 & 1 \\
Biologic complications & 1 & 1 & 0 \\
Marginal secondary caries & 1 & 0 & 1 \\
Periodontal lesion & 1 & 1 & 0 \\
Root fracture & 7 & 5 & 2 \\
Total* & & & \\
\hline${ }^{*}$ All failures were three-unit restorations & & \\
\hline
\end{tabular}

${ }^{*}$ All failures were three-unit restorations.

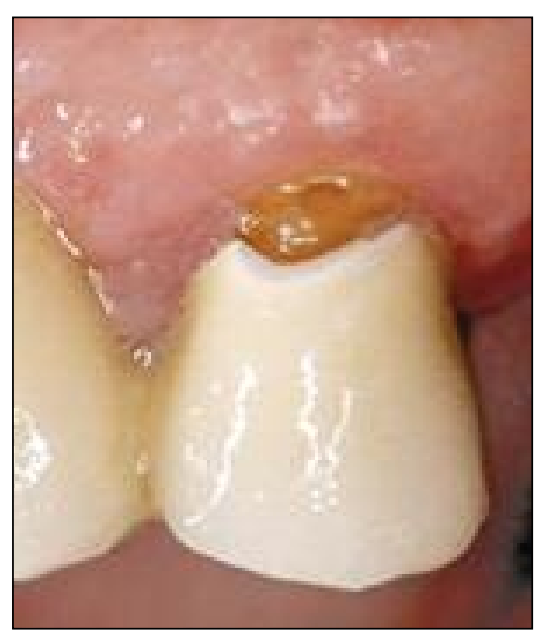

Fig 2 (right) The only recorded framework fracture in terms of a marginal defect.
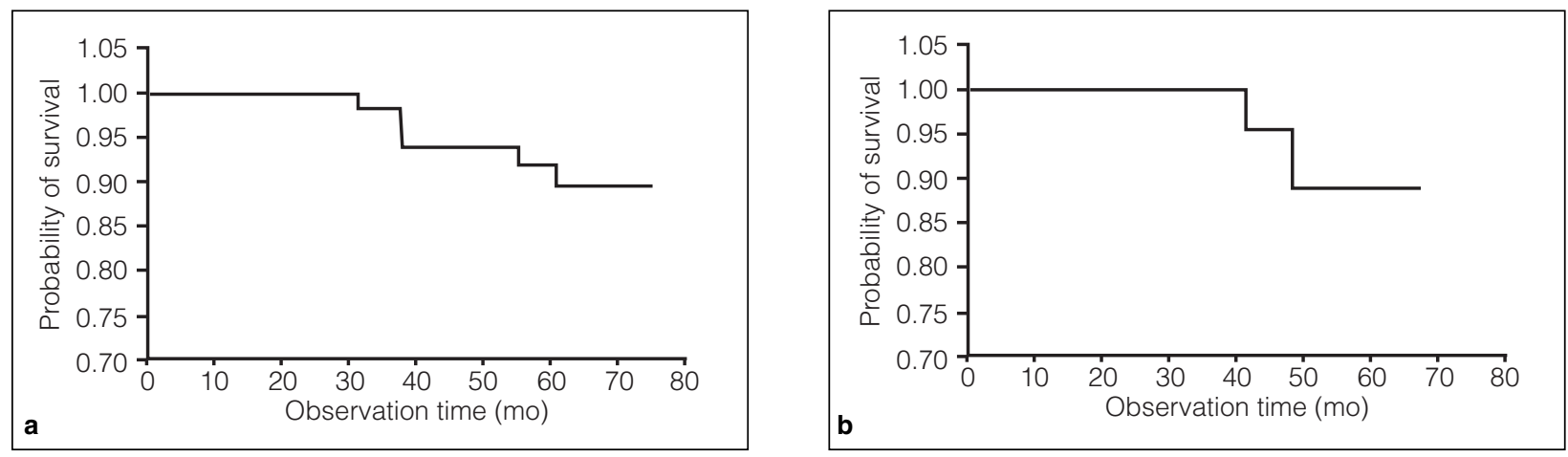

Figs 3a and 3b Survival probabilities of (a) $93.7 \%$ for the experimental group and (b) $95.2 \%$ for the Ceram-S group were found after an observation period of 48 months.

Table 2 Complications and Corresponding Clinical Interventions to Maintain the Restorations In Situ

\begin{tabular}{lccl}
\hline Complication & $\begin{array}{c}\text { Experimental } \\
\text { group }(\mathrm{n}=51)\end{array}$ & $\begin{array}{c}\text { Ceram-S } \\
\text { group }(\mathrm{n}=48)\end{array}$ & Management \\
\hline Chipping of ceramic veneer & 9 & 4 & Polishing \\
Decementation & 1 & 5 & Adhesive recementation \\
Secondary caries & 2 & 1 & Sealing with composite \\
Loss of vitality & 0 & 1 & Endodontic treatment \\
Total & 12 & 11 & \\
\hline
\end{tabular}

The survival rate for the in situ criterion of the experimental group was 93.7\%; in the Ceram-S group, the survival rate reached $95.2 \%$ after an observation period of 48 months (Figs $3 a$ and $3 \mathrm{~b}$ ). Sixty-one FPDs (61.6\%) were observed in situ without any clinical posttreatment (Table 2); 23 restorations required clinical intervention to maintain their function. Apart from the 3 cases where a loss of retention led to total failure, 6 restorations showed a loss of retention, which was managed by recementation of the FPD. The loss of retention occurred main- ly in the mandible (relation of maxilla to mandible: 8:1) and was observed between 11 and 43 months after cementation (mean: $26.3 \pm 12.4$ months). Marginal caries lesions were observed in 4 cases (experimental group: 3, Ceram-S group: 1) (Fig 4). Only one loss of vitality occurred (Ceram-S group, Fig 5). Postoperative hypersensitivity to cold and chewing problems were recorded for 26 of 200 abutment teeth. These symptoms were only temporary and $80 \%$ occurred within the first 13 months after cementation. 
Fig 4 (left) Marginal discoloration in a preliminary secondary caries.

Fig 5 (right) The mandibular left second molar abutment tooth after endodontic treatment. Trepanation caused minor chipping.
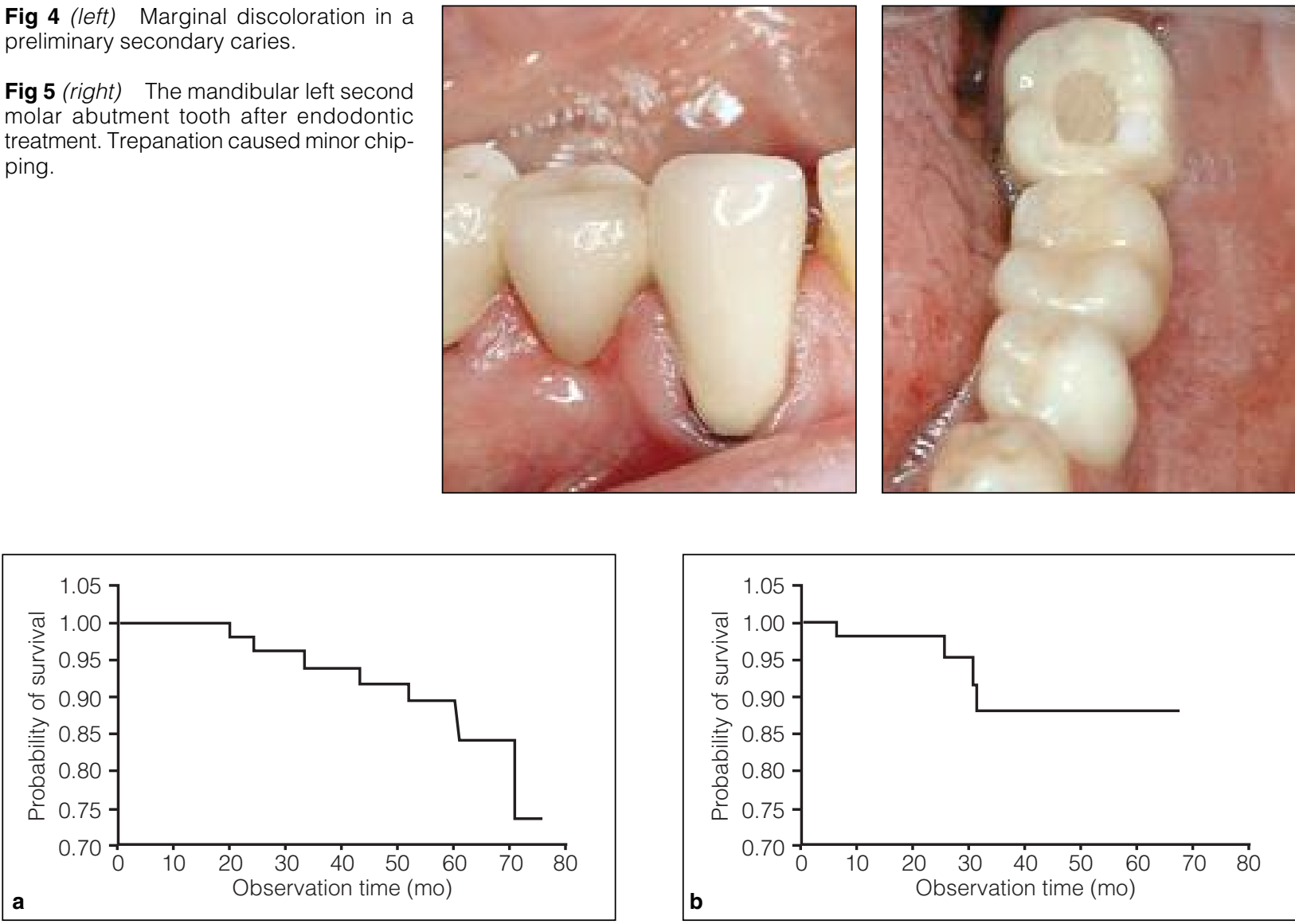

Figs $\mathbf{6 a}$ and $\mathbf{6 b}$ Success probabilities of (a) $91.6 \%$ for experimental ceramic veneers and (b) $88 \%$ for Ceram-S veneers were found after an observation period of 48 months.

A chipping of the veneering material was observed in 9 restorations in the experimental group and 4 specimens in the Ceram-S group. The majority of veneering material events were minor chippings. The probability for success of the ceramic veneers was $91.6 \%$ in the experimental group and $88 \%$ in the Ceram-S group after 48 months (Figs $6 a$ and $6 \mathrm{~b}$ ). The statistical analysis with the log-rank test revealed no significant differences in the time-dependent success rates of the two types of ceramic veneers $(P=.81)$. A chipping of the veneering material was never the reason for removal of the restoration.

\section{Discussion}

In the present study, an overall survival rate of $94 \%$ was determined for zirconia-based posterior FPDs after 4 years of clinical function. This is within the range of data from previously published studies. After short-term service with mean follow-up times of 31 to 37 months, survival rates of $100 \%$ were reported for posterior zirconia-based FPDs. ${ }^{12,14}$ Two studies reported a survival rate of $100 \%$ for zirconiabased posterior FPDs after 5 years of clinical service. ${ }^{11,15}$ Contrary to these findings, Sailer et al ${ }^{10}$ found a survival rate of $73.9 \%$ after 5 years for threeto five-unit zirconia FPDs with a mean observation period of 53 months. The main reason for the replacement of the restorations in that study was secondary caries. Only one framework fractured, leading to a framework survival rate of $97.8 \%$. This is consistent with the overall framework survival rate in the present study (98.9\%) and in good accordance with the results of other clinical trials. ${ }^{11-17}$

The only case of framework fracture determined in this study was not located at a critical position such as the connection area between the abutment and pontic, as expected, but at the vestibular margin of the maxillary right second premolar, analogous to a wedge-shaped defect. The framework fracture could be explained by a locally reduced framework thickness. All data on clinical survival collected up until recently suggest the reliable performance (survival probabilities of $98 \%$ to $100 \%$ after 3 to 5 years) of 


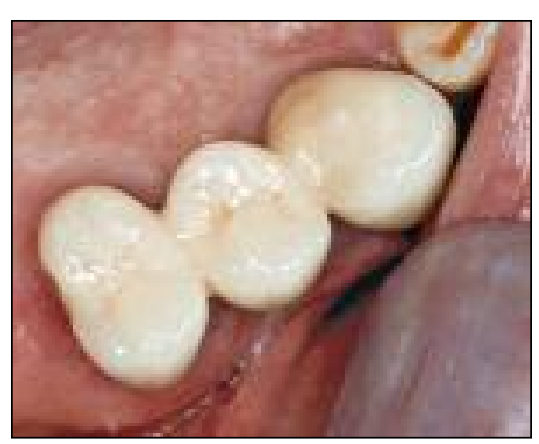

Fig 7a Fracture of the ceramic veneer at the distal aspect of a premolar (occlusal view).

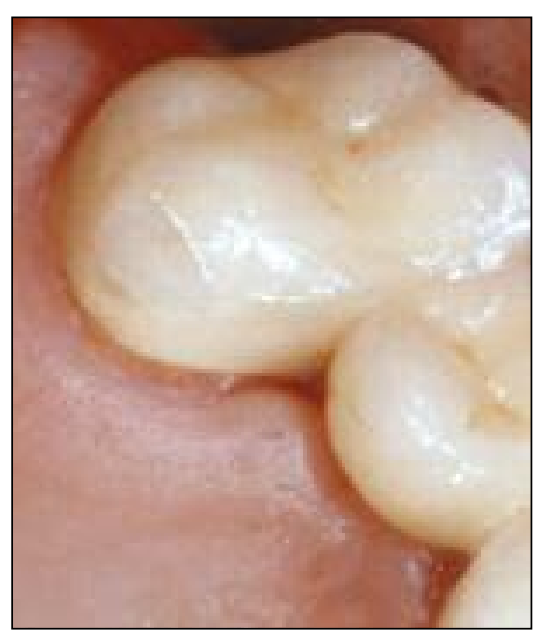

Fig $\mathbf{7 b}$ Minor chipping of the ceramic veneer at the palatal side of a molar.

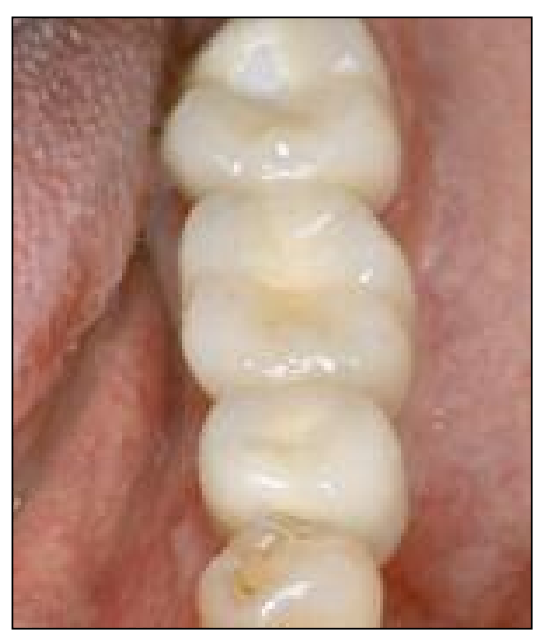

Fig 7c Fracture of the ceramic veneer at the lingual cusp of a mandibular molar. zirconia-based FPD frameworks if the manufacturers' recommendations were followed. ${ }^{10-17}$ A connector cross-section area of at least $9 \mathrm{~mm}^{2}$ should be implemented and the framework thickness should exceed $0.4 \mathrm{~mm}$. In summary, three- and four-unit FPDs offer promising results with a maximum clinical observation time of 5 years.

A review of the relevant literature shows that chipping of the ceramic veneer on zirconia-based restorations is a pressing problem. ${ }^{10-14,17}$ For evaluation periods between 31 and 60 months, chipping rates between $8 \%$ and approximately $30 \%$ have been reported from clinical trials. ${ }^{10-12,14}$ These complications occur mainly in the posterior region. ${ }^{12-14}$ This was supported by the findings of the present study. Chipping rates of $19.6 \%$ for restorations in the experimental group and $8.9 \%$ in the Ceram-S group were recorded. However, Kaplan-Meier analysis revealed that the time-dependent failure rate was not statistically different among groups. After an observation period of 48 months, the success probability for the experimental group was $91.6 \%$. In the Ceram-S group, the success probability was $88 \%$, with no statistical difference when compared to the experimental group (log-rank test, $P=.81$ ). Based on these findings, a variation in the TEC seems to have no significant effect on the success rate of the ceramic veneers in zirconia frameworks. Therefore, the hypothesis of a TEC influencing the durability and chipping rate of the zirconia veneering material is rejected.

Chippings were found just as frequently in the maxilla as in the mandible. This was in contrast to former studies where chippings were only observed in the posterior mandible. ${ }^{12}$ Similar results regarding the chipping rate of the veneering material have been reported by other authors. ${ }^{10,14,16,17}$ This implies a slight inferiority of survival of zirconia frameworks compared to ceramic veneers on metallic frameworks, which display failure rates of $5 \%$ to $8 \%$ after 5 years. ${ }^{18}$ As recently reported, one technical approach to improve the clinical behavior is a strict anatomically oriented framework design that reinforces the ceramic veneer. ${ }^{11}$ All FPDs with chippings remained in function after polishing (Figs 7a and 7b). The most extensive ceramic fracture occurred as a sheering fracture at the lingual cusps of a mandibular molar in the Ceram-S group (Fig 7c). However, the patient decided to keep the restoration. Therefore, the FPD was maintained by polishing the fracture surface.

The main complication leading to the replacement of a restoration was loss of retention, in combination with secondary caries. This was also found in other clinical studies observing the performance of posterior zirconia-based FPDs. ${ }^{10-13}$ In a clinical study evaluating a prototype direct ceramic machining technique, a $21.7 \%$ rate of secondary caries due to marginal gaps was found. This was possibly caused by premature conditions of the scanning and milling technology. ${ }^{10}$ In the present study, marginal secondary caries was found in three units of the experimental group and in one specimen of the Ceram-S group. A possible explanation for the lower rate of secondary caries in the Ceram-S group is the fabrication of the frameworks with updated milling software, launched in early 2003. The updated software for the guidance of the milling process led to an improved marginal fit of the frameworks and therefore decreased the risk of secondary caries. ${ }^{19}$ Moreover, conventional luting might cause an 
Table 3 Complications and Failures According to the Number of Units

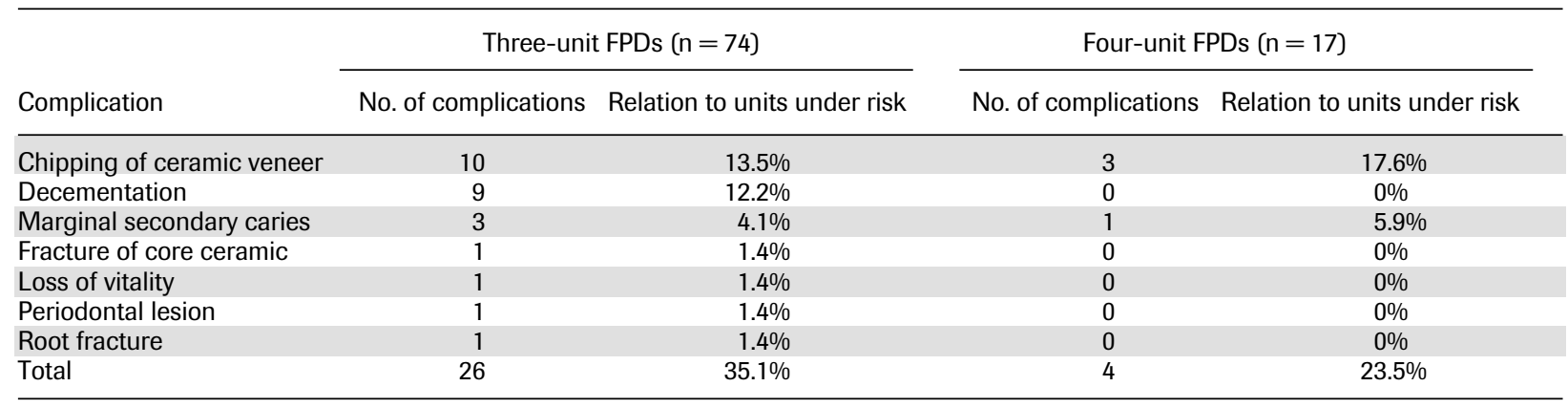

increased risk of secondary caries. It was recently demonstrated that the marginal ditching of zirconiabased FPDs luted with zinc-phosphate cement increased from baseline to the 3-year examination. ${ }^{11}$ This was consistent with the findings of another study showing that microleakage was more extensive for zinc-phosphate cement. ${ }^{20}$ In this study, 9 of 99 restorations showed a loss of retention. In other studies with conventionally luted zirconia FPDs, the rate for loss of retention was $4 \%$ after 5 years of clinical service. ${ }^{12,13}$ An explanation for the high rate of retention loss could be the reduced internal fitting accuracy of the zirconia framework. A recently published in vitro study compared the internal fit of porcelain-fused-to-metal and zirconia-based FPDs. It revealed a reduced internal fit among the zirconia FPDs compared to cast-metal frameworks and therefore, a thicker cement layer. ${ }^{21} \mathrm{~A}$ thicker cement layer as the major cause of error was in line with the outcome of the cast analyses. They revealed that both properly prepared as well as conical abutments were susceptible to retention loss. The majority of the restorations showing a loss of retention were in the mandible. This might be due to the higher flexibility of the mandible. When decementation occurred and the abutment teeth remained intact, the FPDs were reinserted adhesively with an autocuring composite resin cement (Panavia 21, Kuraray). These FPDs remained in function and were not defined as total failures (in contrast to the determinations of other authors). ${ }^{11,12}$ In three cases of retention loss, a caries destruction of at least one abutment tooth impeded recementation.

In the present study, only 1 of 200 abutment teeth lost its vitality and required endodontic treatment, suggesting that this type of prosthodontic reconstruction causes no increased hazard to pulp integrity. This is in line with previously published studies showing no increased risk for endodontic treatment after the insertion of posterior zirconia FPDs. ${ }^{11-14}$ Postoperative hypersensitivity occurred only temporarily. The low incidence of endodontic treatment could be explained by the advanced mechanical strength of the zirconiabased restorations, which allows for more conservative preparation parameters than in other all-ceramic restorations. A $0.8-$ to $1.0-\mathrm{mm}$ shoulder or chamfer preparation was sufficient for a reliable fracture resistance of the restoration. ${ }^{9,12}$ This led to a cutting depth comparable to the preparation design of metal-ceramic restorations, thus reducing the risk of endodontic treatment.

In this study, 81 three-unit and 18 four-unit FPDs were inserted. The small number of four-unit restorations allowed no conclusions regarding higher failure rates in relation to three-unit specimens. However, the complication rates in relation to the total number of restorations investigated seemed to be similar (Table 3).

\section{Conclusions}

Considering the mean observation period of 50 months, the following conclusions can be drawn:

- The survival rates of zirconia-based restorations offer promising results for FPDs in the posterior region.

- The success rates of the ceramic veneers were slightly inferior to those on metallic frameworks, and chipping represented one of the main complications.

- The time-dependent chipping rate of the ceramic veneers was not influenced by a variation in the TEC.

- A loss of retention of the conventionally luted zirconia FPDs was a major reason for failure and complication, especially for restorations placed in the mandible.

- The loss of vitality and the frequency of endodontic treatment did not seem increased compared to metal-ceramic FPDs. 


\section{Acknowledgments}

The authors would like to thank Stephan Kerl and Ulrich Wenzel for their technical assistance and DeguDent for its financial support.

\section{References}

1. Graser GN, Myers ML, Grossmann DG, Cammarato VT. Preliminary clinical evaluation of cast ceramic fixed partial dentures [abstract]. J Dent Res 1985;65:362.

2. Sailer I, Pjetursson BE, Zwahlen M, Hämmerle CH. A systematic review of the survival and complication rates of all-ceramic and metal-ceramic reconstructions after an observation period of at least 3 years. Part II: Fixed partial prostheses. Clin Oral Implants Res 2007;18(suppl 3):86-96 [erratum 2008;19:326-328].

3. Sorensen JA, Kang SK, Torres TJ, Knode H. In-Ceram fixed partial dentures: Three-year clinical trial results. J Calif Dent Assoc 1998;26:207-214.

4. Olsson KG, Fürst B, Andersson B, Carlsson GE. A long-term retrospective and clinical follow-up study of In-Ceram Alumina FPDs. Int J Prosthodont 2003;16:150-156.

5. Marquardt P, Strub JR. Survival rates of IPS empress 2 all-ceramic crowns and fixed partial dentures: Results of a 5-year prospective clinical study. Quintessence Int 2006;37:253-259.

6. Creugers NHJ, Käyser AF, van't Hof MA. A meta-analysis of durability data on conventional fixed bridges. Community Dent Oral Epidemiol 1994;22:448-452.

7. Scurria MS, Bader JD, Shugars DA. Meta-analysis of fixed partial denture survival: Prostheses and abutments. J Prosthet Dent 1998; 79:459-464.

8. Tan K, Pjetursson BE, Lang NP, Chan ES. A systematic review of the survival and complication rates of fixed partial dentures (FPDs) after an observation period of at least 5 years. Clin Oral Implants Res 2004;15:654-666.

9. Tinschert J, Natt G, Mautsch W, Augthun M, Spiekermann H. Fracture resistance of lithium disilicate-, alumina-, and zirconiabased three-unit fixed partial dentures: A laboratory study. Int J Prosthodont 2001;14:231-238.
10. Sailer I, Fehér A, Filser F, Gauckler L, Lüthy H, Hämmerle CH. Fiveyear clinical results of zirconia frameworks for posterior fixed partial dentures. Int J Prosthodont 2007;20:383-388.

11. Molin MK, Karlsson SL. Five-year clinical prospective evaluation of zirconia-based Denzir 3-unit FPDs. Int J Prosthodont 2008;21: 223-227.

12. Tinschert J, Schulze KA, Natt G, Latzke P, Heussen N, Spiekermann $\mathrm{H}$. Clinical behaviour of zirconia-based fixed partial dentures made of DC-Zirkon: 3-year results. Int J Prosthodont 2008;21: 217-222.

13. Tinschert J, Natt G, Latzke P, Schulze KA, Heussen N, Spiekermann H. Bewährung von vollkeramischen Brücken aus DC-Zirkon. 5Jahres-Ergebnisse. ZWR 2007;116:58.

14. Raigrodski AJ, Chiche GJ, Potiket N, et al. The efficacy of posterior three-unit zirconium-oxide-based ceramic fixed partial dental prostheses: A prospective clinical pilot study. J Prosthet Dent 2006;96:237-244.

15. Nothdurft FP, Rountree PR, Pospiech PR. Clinical long-term behavior of Zirconia-based bridges (LAVA): Five years results. J Dent Res 2006;85(special issue C):0312.

16. Pospiech P, Nothdurft FP. Long-term behavior of Zirconia-based bridges: Three year results [abstract]. J Dent Res 2004;83(special issue B):230.

17. Vult von Steyern P, Carlson P, Nilner K. All-ceramic fixed partial dentures designed according to the DC-Zirkon technique. A 2-year clinical study. J Oral Rehabil 2005;32:180-187.

18. Kerschbaum T. Langzeitüberlebensdauer von Zahnersatz-Eine Übersicht. Quintessenz 2004;55:1113-1126.

19. Beuer F, Erdelt KJ, Spiegl K, Gernet W. Marginal and internal fit of CAM milled zirconia crowns. J Dent Res 2004;83(special issue A): 2949.

20. Albert FE, El-Mowafy OM. Marginal adaptation and microleakage of Procera AllCeram crowns with four cements. Int J Prosthodont 2004;17:529-535.

21. Wettstein F, Sailer I, Roos M, Hämmerle CH. Clinical study of the internal gaps of zirconia and metal frameworks for fixed partial dentures. Eur J Oral Sci 2008;116:272-279.

\section{Extent of peri-implantitis-associated bone loss}

The purpose of this retrospective study was to describe the extent that peri-implantitis-associated bone loss is related to implant position. Patient files and intraoral radiographs from 182 previously identified subjects were analyzed. Among the 1,070 implants examined, 419 were found to exhibit peri-implantitis-associated ("progressive") bone loss. The position of each implant was determined in relation to a preceding tooth position. Thus, the implants in the maxilla were assigned positions extending from 17 to 27 and the implants in the mandible were given positions from 47 to 37 . Furthermore, the implants were grouped into either front (13 to 23 or 43 to 33 ) or posterior ( 17 to 14 or 47 to 44 and 24 to 27 or 34 to 37 ) position categories. Four groups of positions were therefore created: upper posterior (UP), upper front (UF), lower posterior (LP), and lower front (LF). The largest frequency of affected implants was found in the lower front (LF) region (52\%). The proportions of affected implants in other positions were $39 \%$ (UF), $35 \%$ (LP), and $30 \%$ (UP). The difference in percentage of affected implants between the LF position and the other regions was statistically significant. The authors concluded that although destructive disease in the tissues surrounding teeth and implants may occur in all areas of the jaws, anatomical aspects in the LF region may render a risk for periodontal and peri-implant bone loss.

Fransson C, Wennström J, Tomasi C, Berglundh T. J Clin Periodontol 2009;36:357-363. References: 14. Reprints: Christer Fransson, Department of Periodontology, The Sahlgrenska Academy at University of Gothenburg, Box 450 S-405 30 Göteborg, Sweden-Seetoh YL, Singapore 